\title{
The transcription factor DECI (stral3, SHARP2) is associated with the hypoxic response and high tumour grade in human breast
}

\section{cancers}

\author{
J Chakrabarti', H Turley', L Campo', C Han², AL Harris², KC Gatter' and SB Fox*,I \\ 'Nuffield Department of Clinical Laboratory Sciences, John Radcliffe Hospital, Oxford OX3 9DU, UK; ${ }^{2}$ Cancer Research UK Molecular Oncology \\ Laboratory, Weatherall Institute of Molecular Medicine, John Radcliffe Hospital, Oxford OX3 9DS, UK
}

\begin{abstract}
DECI, also known as SHARP-2 or Stral3, plays important roles in embryonic development, proliferation, apoptosis and cell differentiation in the mouse. DECI was recently identified as hypoxically induced in CDNA microarray studies of the human renal carcinoma cell line RCC4, to be regulated through hypoxia-inducible factor (HIF)- $\mid \alpha$ and via HIF- $\mid \alpha$, able to block adipocyte differentiation. Nevertheless, its distribution and role in hypoxia and differentiation in human breast cancer are unknown. We therefore examined the pattern and level of expression of DECI using immunohistochemistry in whole tissue sections in normal, in situ and invasive breast carcinomas, and correlated the level of expression of DECI and clinicopathological factors and hypoxic tumour markers in 253 invasive carcinomas on tissue microarrays. We observed an increase in DECl expression during progression from normal to in situ and invasive carcinoma. Expression was not restricted to the tumour cell element but was also observed in endothelial, fibroblasts and inflammatory cells. There was a significant positive correlation between DECI and tumour grade $(P=0.0 \mathrm{I}), \mathrm{HIF}-\mathrm{I} \alpha(P=0.04)$ and the hypoxically regulated gene angiogenin $(P<0.000 \mathrm{I})$, but no significant associations were observed with patient age $(P=0.15)$, lymph node status $(P=0.8)$, tumour size $(P=0.3)$, oestrogen receptor $(P=0.45)$, epidermal growth factor receptor $(P=0.27)$ or Chalkley vessel count $(P=0.45)$. There was no difference in relapse-free $(P=0.84)$ or overall $(P=0.78)$ survival. These findings suggest that DECl plays an important role in the progression to invasive breast cancer and that it may provide a mechanism by which hypoxia blocks tumour differentiation, and may contribute to a more aggressive phenotype. Reversing this phenotype may alter the biological behaviour of individual tumours.

British Journal of Cancer (2004) 91, 954-958. doi:I0.I038/sj.bjc.6602059 www.bjcancer.com

(c) 2004 Cancer Research UK
\end{abstract}

Keywords: DECl; breast; tumours; hypoxia; HIF- $\mid \alpha$

Hypoxia is increasingly recognised to play a major role in determining tumour behaviour being associated with an aggressive phenotype and resistance to chemo- and radiotherapeutic interventions. The transcriptional complex hypoxia-inducible factor (HIF) has emerged as a key regulator mediating many cellular responses necessary to adapt to changes in oxygen tension (reviewed in Maxwell et al, 2001; Goonewardene et al, 2002; Pugh and Ratcliffe, 2003). The HIF complex is composed of a heterodimer of HIF- $1 \alpha$ or HIF- $2 \alpha$ and HIF- $\beta$ (also known as aryl-hydrocarbon nuclear translocator). Hypoxia-inducible factor$\beta$ is constitutively expressed and is involved in several transcriptional systems, whereas the two HIF- $\alpha$ subunits are specific to the hypoxic pathway. In normoxic conditions, the HIF- $\alpha$ units are unstable since two prolyl residues within the oxygen-dependent degradation domains of HIF- $\alpha$ subunits are hydroxylated by prolyl hydroxylases and dioxygen as a co-substrate (reviewed in Pugh and Ratcliffe, 2003). This results in one oxygen being incorporated into the prolyl residue of HIF- $\alpha$, allowing rapid targeting and degradation by the proteasome pathway via the von Hippel-

*Correspondence: Dr SB Fox; E-mail: stephen.fox@ndcls.ox.ac.uk Received 10 March 2004; revised 6 May 2004; accepted 19 July 2004
Lindau (VHL) protein and the ubiquitin E3 ligase complex. However, in hypoxia, as frequently occurs within tumours, there is insufficient oxygen to allow this process resulting in HIF- $\alpha$ stabilisation and translocation to the nucleus, where it is able to bind HIF- $\beta$. The complex then recruits co-activators that bind specific DNA hypoxia response elements (HREs), resulting in increased mRNA transcription.

Many HIF target genes are beneficial to tumour, including those involved in iron metabolism (e.g. transferrin), angiogenesis (e.g. vascular endothelial growth factor), glucose metabolism (glucose transporters), proliferation (insulin growth factor II), endothelial adhesion and $\mathrm{pH}$ regulation (carbonic anhydrase IX) (Zund et al, 1996; Semenza, 2000; Wenger, 2000). Recently, using a cDNA microarray in the renal carcinoma cell line RCC4, which was either defective or competent for VHL, we identified DEC1 (differentially expressed in chondrocytes) to be another such hypoxia-inducible gene (Wykoff et al, 2000b).

DEC1 was originally identified independently by three groups studying different mammalian systems of differentiation (Boudjelal et al, 1997; Rossner et al, 1997; Shen et al, 1997). DEC1 (also known as split and hairy related protein (SHARP) 2 or stimulated with retinoic acid (Stra) 13) is a 412 amino-acid transcription factor whose RNA is expressed in most embryonic and adult 
tissues. DEC1 shows high amino-acid sequence similarity to the Drosophila hairy and enhancer of Split $\mathrm{m} 7$ and mammalian HES1 transcription factors across its basic helix-loop-helix (bHLH) domain, but it lacks the C-terminal WRPW domain that accounts for their transcriptional repressive functions, indicating that DEC1 is a member of a distinct bHLH subfamily. DEC1 binds to DNA, demonstrates transcriptional repressive activity and interacts with several subunits of RNA polymerase II, suggesting that DEC1 represses transcription through modulation of the basal transcriptional machinery and histone deacetylase (Boudjelal et al, 1997; Sun and Taneja, 2000).

DEC1 is reported to have roles in proliferation (Boudjelal et al, 1997), apoptosis (Li et al, 2002) and cell differentiation (Fisher et al, 1996). Indeed, it is possible that DEC1 functions as a HIF effector to mediate the effect of hypoxia on differentiation, since oxygen tension alters differentiation of cytotrophoblast, megakaryocytes, osteochondrocytes, bone marrow cells, adipocytes and neurons (Caniggia et al, 2000; Mostafa et al, 2000; Studer et al, 2000; Lennon et al, 2001; Yun et al, 2002). Nevertheless, since little is known about DEC1 function in human physiological and pathological processes, we raised a polyclonal antibody to investigate the expression profile of DEC1 in normal and neoplastic tissues by immunohistochemistry to help determine its role. This has shown DEC1 to be widely expressed in the nuclei of cells in many tissues, but with a restricted pattern of expression. Although others and we have also reported the expression of DEC1 in several tumour types (Ivanova et al, 2001; Li et al, 2002, 2003; Giatromanolaki et al, 2003), the pattern and level of expression of DEC1 in breast tissues and tumours have not been systematically investigated and the potential role in this tumour type is unknown. Thus, in order to characterise further the significance of DEC1 in normal and neoplastic breast tissues, we have investigated the distribution and level of expression of DEC1 and correlated this with clinicopathological and hypoxic tumour markers in a large series of breast carcinomas.

\section{MATERIALS AND METHODS}

\section{Patients and tumours}

Whole tissue sections from 15 pure in situ breast carcinomas (five low, five intermediate and five high nuclear grade), 101 invasive breast carcinomas and 14 histologically normal breast tissues derived from reduction mammoplasties, together with microarrayed tumour cores from 253 breast carcinomas, were collected from patients undergoing surgery at the John Radcliffe Hospital, Oxford, UK. Tumours were treated by mastectomy $(n=58)$ or lumpectomy $(n=195)$, axillary node sampling with node status confirmed histologically. Primary histological types where known included 188 ductal carcinomas (not otherwise specified), 18 lobular and 15 others. Grading was performed according to the modified Bloom and Richardson method. The clinicopathological characteristics of the series are presented in Table 1. In patients $<50$ years, adjuvant cyclophosphamide, methotrexate and 5fluorouracil (CMF) was administered if tumours were node positive, or oestrogen receptor (ER) negative and/or $\geqslant 3 \mathrm{~cm}$. Patients $\geqslant 50$ years with ER-negative, node-positive tumours also received CMF. The median follow-up was 7.3 (range $0.4-11$ ) years, in which there were 89 relapses and 62 deaths.

\section{DEC1 immunohistochemistry}

Formalin-fixed paraffin-embedded sections $(4 \mu \mathrm{m})$ of normal and primary breast tumours were immunostained with the rabbit polyclonal antibody CW27 as described previously, using the EnVision ${ }^{\text {TM }}$ Detection Kit, Peroxidase/DAB (DAKO, Denmark) (Giatromanolaki et al, 2003). The pattern of DEC1 expression
Table I Correlation analyses between DECI and clinicopathological, angiogenic and hypoxia markers for 253 invasive breast carcinomas studied by tissue microarray

\begin{tabular}{|c|c|c|c|}
\hline & DECI negative & DECI positive & $P$-value \\
\hline No. of patients & 68 & 185 & \\
\hline \multicolumn{4}{|l|}{ Age } \\
\hline $\begin{array}{l}<50 \\
\geqslant 50\end{array}$ & $\begin{array}{l}15 \\
53\end{array}$ & $\begin{array}{r}58 \\
127\end{array}$ & 0.15 \\
\hline \multicolumn{4}{|l|}{ Nodal status } \\
\hline Neg & 37 & 104 & 0.80 \\
\hline Pos & 31 & 81 & \\
\hline \multicolumn{4}{|l|}{ Tumour size $(\mathrm{cm})$} \\
\hline$\leqslant 2 \mathrm{~cm}$ & 41 & 98 & 0.30 \\
\hline$>2 \mathrm{~cm}$ & 27 & 87 & \\
\hline \multicolumn{4}{|l|}{ Grade } \\
\hline I & 19 & 26 & $0.01 *$ \\
\hline$\|$ & 16 & 56 & \\
\hline III & 12 & 56 & \\
\hline \multicolumn{4}{|l|}{$E R$} \\
\hline Neg & 19 & 61 & 0.45 \\
\hline Pos & 49 & 124 & \\
\hline \multicolumn{4}{|l|}{ EGFR } \\
\hline Neg & 30 & 67 & 0.27 \\
\hline Pos & 37 & 114 & \\
\hline \multicolumn{4}{|l|}{ Chalkley count } \\
\hline Low & 3 & 29 & 0.45 \\
\hline High & 5 & 23 & \\
\hline \multicolumn{4}{|l|}{ Angiogenin } \\
\hline Neg & 46 & 76 & $0.000 I^{*}$ \\
\hline Pos & 19 & 101 & \\
\hline \multicolumn{4}{|l|}{$H I F-1 \alpha$} \\
\hline Neg & 54 & 124 & $0.04 *$ \\
\hline Pos & 8 & 42 & \\
\hline
\end{tabular}

$\mathrm{ER}=$ oestrogen receptor; $\mathrm{EGFR}=$ epidermal growth factor receptor; HIF = hypoxiainducible factor. ${ }^{*}$ Denotes significance, where $n<253$ data are unavailable.

was determined from whole tissue sections, whereas the level of nuclear expression was derived using tissue microarrays. One core from the tumour periphery, which is reported to be most biologically relevant (Weidner et al, 1991), and the following scoring system were used: negative $=0$, weak nuclear staining $=1$, moderate nuclear staining $=2$ or strong nuclear staining $=3$. Score 2 and 3 tumours were considered positive for DEC1 in statistical analyses. Two observers assessed the localisation and degree of cellular staining using a conference microscope.

\section{Assessment of HIF- $1 \alpha$, angiogenin and vascularity}

The anti-HIF- $1 \alpha$ protein monoclonal antibody ESEE 122 (Talks et $a l, 2000)$ and rabbit polyclonal antibody against angiogenin (ANG; Santa Cruz Biotechnology; catalogue number sc9044)(Hartmann et al, 1999; Hisai et al, 2003) were applied to sections at dilutions of $1: 40$ and $1: 100$, respectively, followed by the Envision-HRP kit (DAKO, Glostrup, Denmark). Evaluation of HIF- $1 \alpha$ was based on the intensity and extent of nuclear and cytoplasmic reactivity as reported previously (Talks et al, 2000), and angiogenin was scored with the same scoring system as for 
DEC1. Tumour vascularity was counted by scanning at low power $(\times 40-100)$ for the three areas of highest vascularity before using a 25 -point Chalkley point eyepiece graticule at $\times 250\left(0.155 \mathrm{~mm}^{2}\right)$ over these hot spots. The graticule was orientated so that the maximum number of points was on or within areas of highlighted vessels. The mean of three graticule points for each tumour was used in the statistical analysis, with the upper third used as a cut point for categorical analysis as determined previously (Fox et al, 1995).

\section{RESULTS}

\section{DEC1 expression in normal, in situ and invasive breast carcinomas}

Whole tissue sections DEC1 expression in normal human breast tissues was weak and patchy, being mostly present in the nuclei and occasionally in the cytoplasm of the epithelial elements. Expression was present predominantly in the luminal epithelial cells of the acini of terminal duct lobular units and in larger ducts (Figure 1A and B), but myoepithelial cell staining was occasionally

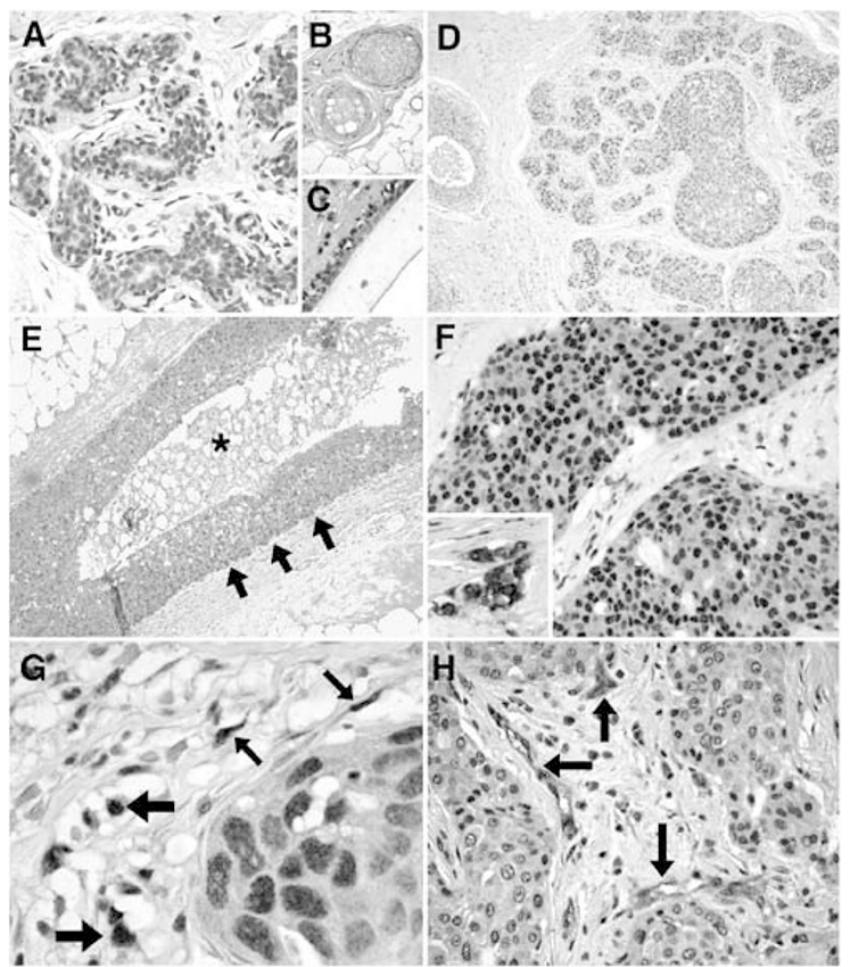

Figure I DECI expression in normal and neoplastic breast tissues Patchy and weak predominantly nuclear DECI expression in luminal epithelial cells of normal acini (A). DECI in endothelial cells and fibroblasts around vessels in normal breast (B). Myoepithelial and luminal DEC in a normal large duct, together with stromal fibroblast positivity (C) Intermediate nuclear grade ductal carcinoma in situ (DCIS) of predominant solid pattern, showing moderate DECI expression that varies within and between involved ducts (D). DECI in high nuclear-grade DCIS of comedo type, showing gradual enhancement of expression towards the periphery of the duct and not immediately adjacent to the necrotic area (asterisk) (E). Strong nuclear and weak cytoplasmic DECI expression in an invasive ductal carcinoma; the inset demonstrates strong nuclear and cytoplasmic staining in a different invasive ductal carcinoma (F). Fibroblast (thin arrows) and macrophage (thick arrows) DECI staining adjacent to an island of invasive ductal carcinoma $(\mathbf{G})$. Strong DECI endothelial cell positivity in tumourassociated vessels in an invasive ductal carcinoma showing weak DEC immunopositivity $(\mathbf{H})$ present, which was enhanced in areas demonstrating myoid metaplasia. The intensity of DEC1 expression was also increased in areas of apocrine and columnar cell metaplasia. Weak DEC1 expression was also observed in stromal cells of the interlobular and intralobular stroma and in endothelial cells of capillaries (Figure 1C). In in situ carcinomas, expression was generally stronger both in the nucleus and the cytoplasm of the neoplastic cells (Figure 1D). One of 15 cases was negative, four cases showed weak staining, five cases moderate staining and five showed strong staining. Expression of DEC1 was variable, both within and between individually affected ducts (Figure 1D). No enhancement was observed adjacent to areas of necrosis and indeed an accentuated expression was observed at the periphery of involved ducts, increasing in the cell layers away from the edge of the necrosis and not immediately adjacent to it (Figure 1E). In the 101 invasive carcinomas, expression of DEC1 was again nuclear but also cytoplasmic in 41 cases, and immunopositivity was stronger and more homogenous throughout the tumour than in normal or in situ carcinomas (Figure 1F). Two tumours were negative, 40 showed weak staining, 24 moderate and 35 strong staining. Other tumour elements were also DEC1 positive, including fibroblasts, macrophages and endothelial cells (Figure $1 \mathrm{G}$ and H) in 86 out of $101(85 \%), 43$ out of $101(42 \%)$ and 79 out of $101(78 \%)$ cases, respectively. Although not graded due to the significant variability in the quantity of these elements, expression was usually stronger than that observed in normal tissues.

Tissue microarrays One $(<1 \%)$ of 253 tumours was negative, 67 $(26 \%)$ cases showed weak staining, 75 (30\%) cases showed moderate staining and $110(44 \%)$ showed strong staining. In all, 68 were considered negative and 185 positive for the statistical analysis. For cytoplasmic staining, 123 (49\%) tumours were positive and $130(51 \%)$ were negative.

\section{Relationship between DEC1 expression, clinicopathological and hypoxic variables and survival}

There was a significant positive correlation in 253 invasive carcinomas from tissue microarrays between DEC1 and tumour grade $(P=0.01)$, HIF- $1 \alpha(P=0.04)$ and the hypoxically regulated gene (Hartmann et al, 1999) angiogenin $(P<0.0001)$. No significant associations were observed with patient age $(P=0.15)$, lymph node status $(P=0.8)$, tumour size $(P=0.3)$, ER $(P=0.45)$, epidermal growth factor receptor $(P=0.27)$ or Chalkley vessel count $(P=0.45)$ (Table 1$)$. There was no difference in relapse-free $(P=0.84)$ or overall $(P=0.78)$ survival in a univariate analysis of patients when tumours were stratified by DEC1 expression (Figure 2).

\section{DISCUSSION}

DEC1 is a new and structurally different class of bHLH protein. Although little is known about its function in human physiological and pathological processes, in the mouse DEC1 represses adipocyte, mesodermal and endodermal differentiation but promotes neuronal differentiation (Boudjelal et al, 1997; Yun et al, 2002). It may also play a role in regulating peripheral T-cell tolerance through elimination of activated lymphocytes (Sun et al, 2001), affect cell proliferation (Sun and Taneja, 2000) and apoptosis ( $\mathrm{Li}$ et al, 2002). We and others have identified DEC1 as a VHL target gene (Ivanov et al, 1998; Wykoff et al, $2000 \mathrm{~b})$. In view of the potential of DEC1 to regulate the cellular responses to hypoxia in neoplasia through the above processes, we have examined the pattern and level of expression of DEC1 in normal and neoplastic human breast tissues. In normal breast, we observed only a low level and 

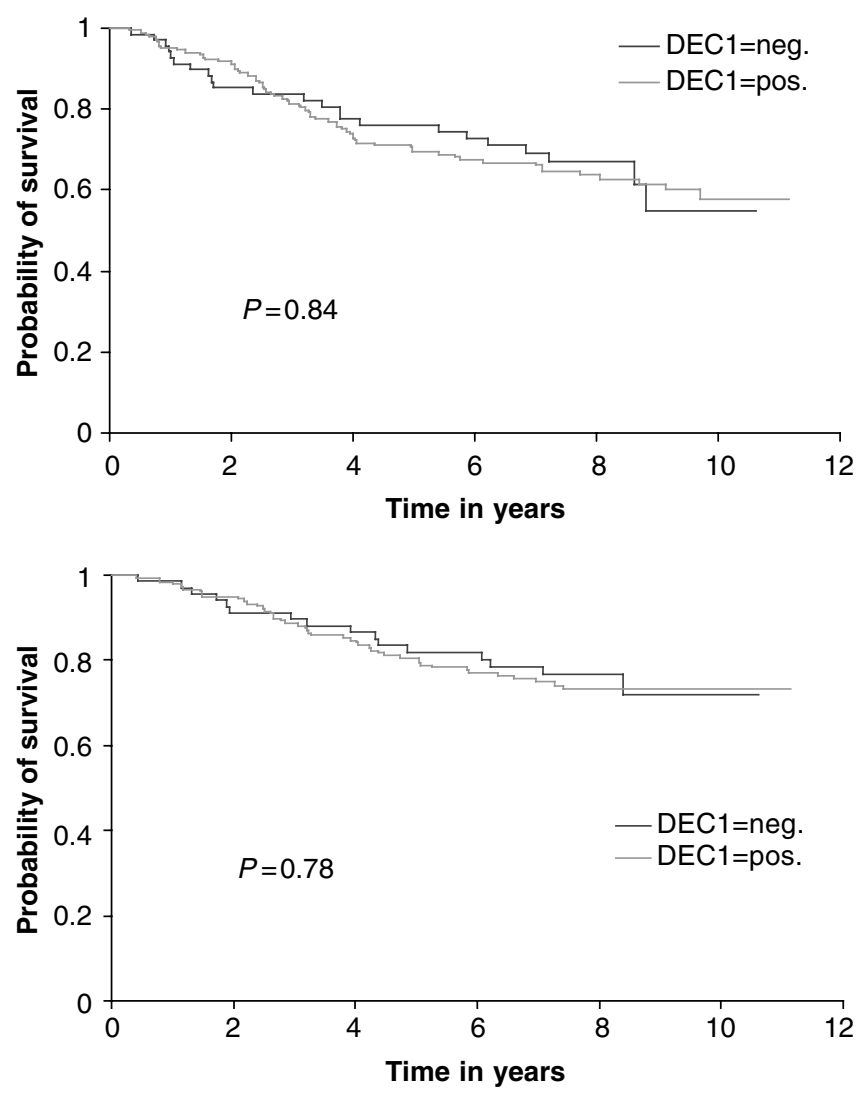

Figure 2 Kaplan and Meier relapse-free survival (upper graph) and overall survival curves (lower graph) stratified by DECI expression.

patchy expression of DEC1, suggesting that it is unlikely to play a role in normal cyclical physiological changes. However, there was increased expression of DEC1 in metaplastic changes, in keeping with its role in cellular differentiation (Shapland et al, 1988; Fisher et al, 1996).

The incremental increase in DEC1 expression in both the nuclear and cytoplasmic neoplastic cell compartments during progression of normal to in situ and invasive carcinoma suggests that DEC1 plays a role in breast cancer progression. It may additionally have a role in stroma since expression was frequently observed particularly in fibroblasts and endothelium. However, the mechanism of DEC1 regulation in tumour cells must be VHL independent since, unlike conventional clear-cell renal cell carcinomas, breast cancers have an intact VHL gene. This is emphasised by the strong DEC1 staining of other tumour elements, including endothelial cells that are genotypically normal. Although little is known about the regulation of DEC1, prostaglandin E2 and transforming growth factor (TGF)- $\beta$ have been reported to induce DEC1, TGF- $\beta$ being frequently expressed in breast carcinomas (Zawel et al, 2002; Bek et al, 2003).

Since Stra13 is associated with growth arrest, the increase in DEC1 expression in tumours may seem paradoxical (Boudjelal et al, 1997; Sun and Taneja, 2000). However, the level of expression alters the effect, with medium levels resulting in an increased proliferation rate of approximately two- to three-fold, with the higher-expressing clones not being viable (Boudjelal et al, 1997; Sun and Taneja, 2000).

DEC1 is induced by hypoxia through a HRE (Miyazaki et al, 2002), and in our study we have demonstrated a significant association with HIF- $1 \alpha$ and the hypoxia-induced gene angiogenin
(Hartmann et al, 1999), supporting its induction by this microenvironmental stress in breast cancer. Nevertheless, unlike CAIX (Wykoff et al, 2000a), we did not observe upregulation of DEC1 immediately adjacent to areas of necrosis in either in situ or invasive carcinomas, similar to findings obtained by mRNA in situ hybridisation studies (Peter Watson, personal communication). Indeed, DEC1 was increasingly expressed in cell layers distant from the edge of the necrotic zone. This pattern of expression overlaps with that of CAIX and HIF- $1 \alpha$, with HIF- $1 \alpha$ located throughout tumours, showing that there is a differential pattern of localisation of hypoxia-associated molecules. The reasons for this are not clear, but may reflect the different half-lives of the proteins and/or regulation by other factors such as TGF- $\beta$, the latter of which is associated with breast cancer progression (Gorsch et al, 1992; Zawel et al, 2002).

Nevertheless, the marked induction of this differentiation factor by hypoxia within tumours suggests that it may be predominantly regulated by hypoxia and that hypoxia may have a role in differentiation. Indeed, a positive association between tumour grade and HIF- $1 \alpha$ has been reported. Thus, the significant positive correlation between high DEC1 expression and high tumour grade that we describe, an association that has been reported in lung cancers (Giatromanolaki et al, 2003) is in accordance with its induction by HIF (Bos et al, 2001) and Stra13's ability to repress differentiation in embryogenesis and adipocytes (Boudjelal et al, 1997; Yun et al, 2002). The mechanism of this repression may be through interaction with other transcription factors such as TFB, TFIIB and USF, since DEC1, unlike other family members, does not bind to $\mathrm{E}$ box, $\mathrm{N}$ box or $\mathrm{C}$ box sequences (Yun et al, 2002). DEC1 is also reported to antagonise serum deprivation-induced apoptosis through selective repression of pro-caspases 3, 7 and 9, but not 8 , suggesting the blockage of mitochondrial apoptotic pathways (Li et al, 2002). Thus, DEC1 may play a further role in rescuing high-grade tumours from widespread programmed cell death (Gandhi et al, 1998).

Although our findings suggest that DEC1 may contribute to mediating the aggressive phenotype of hypoxic tumours, we did not demonstrate a significant association between DEC1-positive tumours and relapse-free or overall survival that has been reported for hypoxic node-negative and node-positive breast tumours (Schindl et al, 2002; Bos et al, 2003). This is likely to be due to the accumulated effects of the many classes of genes that the HIF response activates. Nevertheless, data derived from mouse podocytes suggest that DEC1 may play an important cytoprotective role against reactive oxygen species through upregulating haeme oxygenase-1 and decreasing NADPH oxidase (Bek et al, 2003). Thus, the level of DEC1 in tumours should be assessed for a relation in response to radiotherapy.

Recently, DEC2, a human DEC1 homologue, has been cloned and has also been shown to be hypoxically induced (Fujimoto et al, 2001; Miyazaki et al, 2002). Data to date suggest that, whereas DEC1 is mostly expressed in cancer, DEC2 expression is higher in the adjacent normal tissues. Indeed, forced expression of DEC1 resulted in repression in the activity of a DEC2 promoter reporter (Azmi et al, 2003). It will thus be of interest to establish the role of this protein in the hypoxic pathway.

In summary, we have shown that DEC1 expression increases on progression from normal to in situ and invasive carcinoma, supporting a significant role for this transcription factor in breast neoplasia. We have further shown that DEC1 expression is strongly associated with HIF- $1 \alpha$, the hypoxically induced protein angiogenin and tumour grade, suggesting a role for DEC1 in blocking tumour differentiation and potentially apoptosis. These findings provide mechanisms by which breast tumours in a hypoxic environment acquire a more aggressive phenotype (Schindl et al, 2002). 


\section{REFERENCES}

Azmi S, Sun H, Ozog A, Taneja R (2003) mSharp-1/DEC2, a basic helixloop-helix protein functions as a transcriptional repressor of $\mathrm{E}$ box activity and Stra13 expression. J Biol Chem 278: 20098-20109

Bek MJ, Wahle S, Muller B, Benzing T, Huber TB, Kretzler M, Cohen C, Busse-Grawitz A, Pavenstadt H (2003) Stra13, a prostaglandin E2induced gene, regulates the cellular redox state of podocytes. FASEB J 17: $682-684$

Bos R, van der Groep P, Greijer AE, Shvarts A, Meijer S, Pinedo HM, Semenza GL, van Diest PJ, van der Wall E (2003) Levels of hypoxiainducible factor-1alpha independently predict prognosis in patients with lymph node negative breast carcinoma. Cancer 97: 1573-1581

Bos R, Zhong H, Hanrahan CF, Mommers EC, Semenza GL, Pinedo HM, Abeloff MD, Simons JW, van Diest PJ, van der Wall E (2001) Levels of hypoxia-inducible factor-1 alpha during breast carcinogenesis. J Natl Cancer Inst 93: $309-314$

Boudjelal M, Taneja R, Matsubara S, Bouillet P, Dolle P, Chambon P (1997) Overexpression of Stra13, a novel retinoic acid-inducible gene of the basic helix-loop-helix family, inhibits mesodermal and promotes neuronal differentiation of P19 cells. Genes Dev 11: 2052-2065

Caniggia I, Mostachfi H, Winter J, Gassmann M, Lye SJ, Kuliszewski M, Post M (2000) Hypoxia-inducible factor-1 mediates the biological effects of oxygen on human trophoblast differentiation through TGFbeta(3). J Clin Invest 105: $577-587$

Fisher AL, Ohsako S, Caudy M (1996) The WRPW motif of the hairy-related basic helix-loop-helix repressor proteins acts as a 4-amino-acid transcription repression and protein-protein interaction domain. Mol Cell Biol 16: $2670-2677$

Fox SB, Leek RD, Weekes MP, Whitehouse RM, Gatter KC, Harris AL (1995) Quantitation and prognostic value of breast cancer angiogenesis: comparison of microvessel density, Chalkley count, and computer image analysis. J Pathol 177: 275-283

Fujimoto K, Shen M, Noshiro M, Matsubara K, Shingu S, Honda K, Yoshida E, Suardita K, Matsuda Y, Kato Y (2001) Molecular cloning and characterization of DEC2, a new member of basic helix-loop-helix proteins. Biochem Biophys Res Commun 280: 164-171

Gandhi A, Holland PA, Knox WF, Potten CS, Bundred NJ (1998) Evidence of significant apoptosis in poorly differentiated ductal carcinoma in situ of the breast. $\mathrm{Br}$ J Cancer 78: $788-794$

Giatromanolaki A, Koukourakis MI, Sivridis E, Turley H, Wykoff CC, Gatter KC, Harris AL (2003) DEC1 (STRA13) protein expression relates to hypoxia-inducible factor 1-alpha and carbonic anhydrase-9 overexpression in non-small cell lung cancer. J Pathol 200: 222-228

Goonewardene TI, Sowter HM, Harris AL (2002) Hypoxia-induced pathways in breast cancer. Microsc Res Tech 59: $41-48$

Gorsch SM, Memoli VA, Stukel TA, Gold LI, Arrick BA (1992) Immunohistochemical staining for transforming growth factor beta 1 associates with disease progression in human breast cancer. Cancer Res 52: $6949-6952$

Hartmann A, Kunz M, Kostlin S, Gillitzer R, Toksoy A, Brocker EB, Klein CE (1999) Hypoxia-induced up-regulation of angiogenin in human malignant melanoma. Cancer Res 59: $1578-1583$

Hisai H, Kato J, Kobune M, Murakami T, Miyanishi K, Takahashi M, Yoshizaki N, Takimoto R, Terui T, Niitsu Y (2003) Increased expression of angiogenin in hepatocellular carcinoma in correlation with tumor vascularity. Clin Cancer Res 9: 4852-4859

Ivanov SV, Kuzmin I, Wei MH, Pack S, Geil L, Johnson BE, Stanbridge EJ, Lerman MI (1998) Down-regulation of transmembrane carbonic anhydrases in renal cell carcinoma cell lines by wild-type von HippelLindau transgenes. Proc Natl Acad Sci USA 95: 12596-12601

Ivanova AV, Ivanov SV, Danilkovitch-Miagkova A, Lerman MI (2001) Regulation of STRA13 by the von Hippel-Lindau tumor suppressor protein, hypoxia, and the UBC9/ubiquitin proteasome degradation pathway. J Biol Chem 276: $15306-15315$

Lennon DP, Edmison JM, Caplan AI (2001) Cultivation of rat marrowderived mesenchymal stem cells in reduced oxygen tension: effects on in vitro and in vivo osteochondrogenesis. J Cell Physiol 187: $345-355$

Li Y, Xie M, Song X, Gragen S, Sachdeva K, Wan Y, Yan B (2003) DEC1 negatively regulates the expression of DEC2 through binding to the Ebox in the proximal promoter. J Biol Chem 278: $16899-16907$

Li Y, Zhang H, Xie M, Hu M, Ge S, Yang D, Wan Y, Yan B (2002) Abundant expression of Dec1/stra13/sharp2 in colon carcinoma: its antagonizing role in serum deprivation-induced apoptosis and selective inhibition of procaspase activation. Biochem J 367: $413-422$

Maxwell PH, Pugh CW, Ratcliffe PJ (2001) Activation of the HIF pathway in cancer. Curr Opin Genet Dev 11: 293-299

Miyazaki K, Kawamoto T, Tanimoto K, Nishiyama M, Honda H, Kato Y (2002) Identification of functional hypoxia response elements in the promoter region of the DEC1 and DEC2 genes. J Biol Chem 277: $47014-47021$

Mostafa SS, Miller WM, Papoutsakis ET (2000) Oxygen tension influences the differentiation, maturation and apoptosis of human megakaryocytes. Br J Haematol 111: $879-889$

Pugh CW, Ratcliffe PJ (2003) The von Hippel-Lindau tumor suppressor, hypoxia-inducible factor-1 (HIF-1) degradation, and cancer pathogenesis. Semin Cancer Biol 13: $83-89$

Rossner MJ, Dorr J, Gass P, Schwab MH, Nave KA (1997) SHARPs: mammalian enhancer-of-split- and hairy-related proteins coupled to neuronal stimulation. Mol Cell Neurosci 9: 460-475

Schindl M, Schoppmann SF, Samonigg H, Hausmaninger H, Kwasny W, Gnant M, Jakesz R, Kubista E, Birner P, Oberhuber G (2002) Overexpression of hypoxia-inducible factor 1alpha is associated with an unfavorable prognosis in lymph node-positive breast cancer. Clin Cancer Res 8: $1831-1837$

Semenza GL (2000) HIF-1: mediator of physiological and pathophysiological responses to hypoxia. J Appl Physiol 88: $1474-1480$

Shapland C, Lowings P, Lawson D (1988) Identification of new actinassociated polypeptides that are modified by viral transformation and changes in cell shape. J Cell Biol 107: $153-161$

Shen M, Kawamoto T, Yan W, Nakamasu K, Tamagami M, Koyano Y, Noshiro M, Kato Y (1997) Molecular characterization of the novel basic helix-loop-helix protein DEC1 expressed in differentiated human embryo chondrocytes. Biochem Biophys Res Commun 236: $294-298$

Studer L, Csete M, Lee SH, Kabbani N, Walikonis J, Wold B, McKay R (2000) Enhanced proliferation, survival, and dopaminergic differentiation of CNS precursors in lowered oxygen. J Neurosci 20: $7377-7383$

Sun H, Taneja R (2000) Stra13 expression is associated with growth arrest and represses transcription through histone deacetylase (HDAC)dependent and HDAC-independent mechanisms. Proc Natl Acad Sci USA 97: $4058-4063$

Sun H, Lu B, Li RQ, Flavell RA, Taneja R (2001) Defective T cell activation and autoimmune disorder in Stra13-deficient mice. Nat Immunol 2: 1040 - 1047

Talks KL, Turley H, Gatter KC, Maxwell PH, Pugh CW, Ratcliffe PJ, Harris AL (2000) The expression and distribution of the hypoxia-inducible factors HIF-1alpha and HIF-2alpha in normal human tissues, cancers, and tumor-associated macrophages. Am J Pathol 157: 411-421

Weidner N, Semple JP, Welch WR, Folkman J (1991) Tumor angiogenesis and metastasis - correlation in invasive breast carcinoma. $N$ Engl J Med 324: $1-8$

Wenger RH (2000) Mammalian oxygen sensing, signalling and gene regulation. J Exp Biol 203(Part 8): 1253-1263

Wykoff CC, Beasley NJ, Watson PH, Turner KJ, Pastorek J, Sibtain A, Wilson GD, Turley H, Talks KL, Maxwell PH, Pugh CW, Ratcliffe PJ, Harris AL (2000a) Hypoxia-inducible expression of tumor-associated carbonic anhydrases. Cancer Res 60: 7075-7083

Wykoff CC, Pugh CW, Maxwell PH, Harris AL, Ratcliffe PJ (2000b) Identification of novel hypoxia dependent and independent target genes of the von Hippel-Lindau (VHL) tumour suppressor by mRNA differential expression profiling. Oncogene 19: 6297-6305

Yun Z, Maecker HL, Johnson RS, Giaccia AJ (2002) Inhibition of PPAR gamma 2 gene expression by the HIF-1-regulated gene DEC1/Stra13: a mechanism for regulation of adipogenesis by hypoxia. Dev Cell 2: $331-341$

Zawel L, Yu J, Torrance CJ, Markowitz S, Kinzler KW, Vogelstein B, Zhou S (2002) DEC1 is a downstream target of TGF-beta with sequence-specific transcriptional repressor activities. Proc Natl Acad Sci USA 99: $2848-2853$

Zund G, Nelson DP, Neufeld EJ, Dzus AL, Bischoff J, Mayer JE, Colgan SP (1996) Hypoxia enhances stimulus-dependent induction of E-selectin on aortic endothelial cells. Proc Natl Acad Sci USA 93: 7075-7080 